\title{
SELEÇÃO DE LIVROS NAS BIBLIOTECAS UNIVERSITÁRIAS SOB A ÓTICA DOS BIBLIOTECÁRIOS BRASILEIROS
}

\section{SELECTION OF BOOKS IN UNIVERSITY LIBRARIES UNDER THE VIEW OF BRAZILIAN LIBRARIES}

\author{
Daniela Eugênia Moura de Albuquerquea \\ Antonio de Souza Silva Junior ${ }^{b}$ \\ Murilo Artur Araújo da Silveira
}

\begin{abstract}
RESUMO
Introdução: A seleção de livros é um processo complexo caracterizado por aspectos socioculturais, humanísticos, técnicos, em que os critérios são fundamentais para nortear os bibliotecários nas tomadas de decisões. Objetivo: Tem como objetivo central identificar os critérios de indispensáveis para o processo de tomada de decisão de seleção de livros nas bibliotecas públicas universitárias brasileiras. Metodologia: Configura-se como uma pesquisa exploratória que utiliza a técnica de análise de conteúdo e de regressão linear múltipla em duas etapas: quantitativa e qualitativa. A amostra da etapa quantitativa foi composta por 140 respondentes e a realização da coleta de dados foi mediante a aplicação de questionários embasada na literatura científica nacional e internacional. Na etapa qualitativa a amostra foi de 15 entrevistados e os dados foram coletados através de entrevistas semiestruturadas. A análise e o diagnóstico dos dados quantitativos foram realizados a partir do desenvolvimento do método de regressão linear múltipla e os dados qualitativos foram por meio da análise pragmática da linguagem. Resultados: Conclui que o processo de seleção pode ser explicado através da variável atualidade da informação descrita como única utilizada pelos bibliotecários das universidades públicas do Brasil. Conclusões: Em contraponto à literatura, manter a informação atualizada se mostra como a critério significativo, no tocante ao desenvolvimento de coleções pelos bibliotecários das Universitárias públicas do Brasil.
\end{abstract}

Descritores: Seleção de livros. Bibliotecas Universitárias. Bibliotecários. Brasil.

\footnotetext{
a Mestranda do Programa de Pós-graduação em Ciência da Informação na Universidade Federal de Pernambuco (PPGCI-UFPE). E-mail: danielaeugenia@outlook.com

b Docente do Departamento de Ciência da Informação da Universidade Federal de Pernambuco (PPGCl-UFPE). E-mail: silvajunior.as@gmail.com

c Docente do Departamento de Ciência da Informação da Universidade Federal de Pernambuco (PPGCl-UFPE). E-mail: muriloas@gmail.com
} 


\section{INTRODUÇÃO}

O paradigma custodial, historicista e patrimonialista que permeou as bibliotecas durante o curso dos séculos passou por mudanças. $\mathrm{O}$ acesso à informação foi, aos poucos, difundido nas unidades organizacionais, sendo ampliado e atualizado pelo surgimento das Tecnologias da Informação e Comunicação (TIC). Os recursos tecnológicos, agora, auxiliam na disseminação de informações com vistas à promoção do acesso às informações, em contraposição ao que antes existia: o distanciamento entre o bibliotecário e os seus usuários (MELO; MARQUES; PINHO, 2014).

Diante disso, as funções do bibliotecário foram reposicionadas para, essencialmente, "[...] fornecer a informação certa, da fonte certa, ao cliente certo, no momento certo, de forma certa e a um custo que justifique seu uso". (MELO; MARQUES; PINHO, 2014, p. 76).

A seleção de livros está inserida do processo de Formação e Desenvolvimento de Coleções (FDC), na qual depende de outras atividades como o estudo da comunidade, as políticas de seleção, aquisição, desbastamento e avaliação para que haja um crescimento dinâmico e qualitativo dos acervos que estejam voltados para o público. Litton (1975) já à época comentava acerca da seleção de livros como uma profissão que merece um reconhecimento e como uma especialidade no universo da Biblioteconomia, como a catalogação, o serviço de referência e o de circulação.

O processo de FDC reúne um conjunto de práticas antigas e suas aplicações sempre estiveram voltadas para abrigar as coleções, mas, com a explosão informacional, marcada pela pós-Segunda Guerra Mundial, surgiram dificuldades em como selecionar e guardar a demasia dos materiais bibliográficos como esclarece (SANTA ANNA, 2016).

O papel das bibliotecas, principalmente no século XXI "[...] deve ser necessariamente um espaço de novidades e descobertas, e o bibliotecário 0 agente articulador deste lócus de inovação." (BRAYNER, 2018, p. 22). À vista disso, é onde entram as Bibliotecas Universitárias (BU). As BU são caracterizadas por serem consideradas organizações dependentes, complexas 
e com múltiplas funções, na qual sua comunidade abrange um público de professores, alunos, técnicos, pesquisadores e usuários potenciais. É uma das tipologias que é responsável acentuadamente pela produção científica e tecnológica (SILVA, 2009).

Ao estudar a realidade das BU públicas brasileiras, as publicações se debruçam sobre o estudo e a comparação dos procedimentos utilizados para a FDC de material nas BU com os preceitos da literatura da área. A adequação das recomendações propostas pelos modelos teóricos diverge, mas é deixada clara a necessidade de haver uma política de desenvolvimento de coleções para nortear e fundamentar as ações de constante adequação da coleção às necessidades demandadas pela comunidade universitária (ALMEIDA; MACHADO, 2017; EDUVIRGES, 2013; FARIA, 2017; MATTOS; DIAS, 2009; SANTA ANNA, 2017; SILVA; AMARAL; PAJEÚ, 2018; TAVARES, 2015).

Os autores supracitados ratificam a necessidade de que sejam estabelecidos critérios na seleção. É necessário que as informações disponibilizadas sejam: relevantes, confiáveis, atuais, ajustadas às demandas e expectativas dos usuários, o autor tenha autoridade reconhecida, exista um número de usuários potenciais que poderão utilizar o material e também escassez de material sobre o assunto na coleção da biblioteca. (MIRANDA, 2007; MIRANDA; GALLOTTI; CECATTO, 2017; MIRANDA; BERNARDINO, 2019; SANTA ANNA, 2016).

O texto inicia com traços contextuais acerca do processo de seleção de livros de uma maneira ampla e depois nas $\mathrm{BU}$, fazendo uma ponte com os critérios de seleção mais conhecidos e utilizados. Em seguida, são apresentados os métodos e resultados das etapas quantitativa e qualitativa sobre os critérios mais significativos para a seleção de livros nas BU públicas e federais do Brasil de acordo com o cenário atual.

\section{SELEÇÃO DE LIVROS}

O processo de seleção das unidades organizacionais é inerente para o adequado funcionamento das bibliotecas. Para que a coleção cresça de maneira 
ordenada e racional, é preciso antes ter estudado a comunidade, seguindo o modelo proposto por $\mathrm{G}$. Edward Evans, para que o profissional da informação possa criar uma política de seleção de acordo com as necessidades dos usuários.

Figueiredo (1984, p. 138) afirma que "uma coleção selecionada e desenvolvida conforme os interesses e necessidades de seus usuários torna mais fácil o acesso a recuperação e a disseminação da informação." Se o bibliotecário/comissão de seleção não conhecerem o seu público respeitando o serviço de informação na qual a biblioteca está inserida, o trabalho de escolher os itens pode se tornar superficial e a biblioteca poderá adquirir livros que nunca serão usados, acarretando prejuízos, um deles seria o financeiro, devido ao recurso orçamentário disponibilizado pela instituição mantenedora.

O processo de seleção sempre deve existir, independentemente das tecnologias que promovem benefícios para as bibliotecas, pois ainda as máquinas não conseguem realizar o trabalho que exige uma complexidade e diversos atributos do bibliotecário selecionador. As unidades organizacionais não podem adquirir todo tipo de livro, só para encher suas estantes, quando isso acontece, ou seja, quando a biblioteca adquire obras que não tem significado nenhum em seu escopo, essa obra permanecerá durante anos no mesmo lugar, empoeirada e inutilizada.

Figueiredo (1984, p. 137) já discutia sobre essa questão há mais de 30 anos, corroborando com sua declaração de que, "Sempre deverá, portanto, existir seleção, até nas maiores bibliotecas. Nem todos os livros têm valor permanente, e muitos livros nem mesmo têm valor. Somente grandes livros são clássicos, imortais".

Miranda (1980, p. 68) já afirmava que "o processo de seleção é, das tarefas profissionais, a que melhor orienta os serviços futuros da biblioteca" e Weitzel (2006, p. 19) na mesma linha de pensamento diz que "[...] não é possível desenvolver coleções sem avaliar ou selecionar [...]" Logo, nota-se o quão importante é o estabelecimento de uma política de seleção, que de maneira geral é a reunião dos critérios de seleção (VERGUEIRO, 2010) para que o processo ocorra de forma harmoniosa e que atenda principalmente as necessidades informacionais dos clientes e os objetivos da instituição. 
Vergueiro (1989, p. 38) aponta que "[...] a atividade de seleção não poderia nunca ter sua importância subestimada [...]". Tanto na área da biblioteca quanto na acadêmica, os estudos de seleção devem sempre ganhar espaço nas pesquisas e consequentemente nas adequações as mudanças do contexto da unidade organizacional.

Vergueiro (1989) atesta que, antigamente, o processo de seleção era visto como uma arte, o que para o autor não era bom para o trabalho do bibliotecário nessa área. No decorrer dos anos, as técnicas especializadas foram enaltecidas e a visão do processo de seleção como arte foi sendo aos poucos esquecida. Porém, Tallman e Work (2018) valorizam a junção da arte e da ciência nas atividades de seleção.

A importância nas técnicas nessa etapa é fundamental, pois o selecionador não agirá sendo parcial, ou colocando na totalidade as suas influências nas tomadas de decisões (pois não se pode esquecer do elemento humano), mas seguirá as políticas já antes estabelecidas por uma comissão, ou seja, o profissional da informação nunca deve atuar sozinho, ele precisa de uma equipe multidisciplinar que vise os objetivos da instituição e dos usuários. Umas das demandas técnicas da seleção é o alto grau de detalhamento (VERGUEIRO, 2010), na qual os responsáveis devem ser cautelosos, objetivos e imparciais.

Nas publicações científicas internacionais, a seleção é umas das peças fundamentais da FDC (DRURY, 1930, KITAJIMA; BABA; MINAMI, 2015). Um dos autores mais conhecidos nessa área, afirmava que "[...] a seleção dos livros é uma função essencial que não deve ser negligenciada ou relegada a momentos ímpares." (DRURY, 1930, p. 3, tradução nossa).

A seleção de materiais bibliográficos envolve capacidades intelectuais (DIAS; PIRES, 2003; LITTON, 1975; VERGUEIRO, 1989; 2010) em lidar com diversos ramos do universo dos livros e principalmente em estudar o público para a qual a biblioteca está servindo, sabendo que ao decorrer dos tempos esse mesmo público passará por mudanças, entrarão novos usuários com outras necessidades informacionais. Selecionar livros não é trabalhar com certezas, diferentemente do campo das exatas, que muitas vezes lhe dá a resposta definitiva (LITTON, 1975). 


\subsection{Seleção de Livros nas Bibliotecas Universitárias}

No ambiente acadêmico, a seleção de livros deve ser seguida por uma política de seleção que norteará o bibliotecário responsável por esse processo. As diretrizes de seleção devem estar inseridas na política de FDC, pois a biblioteca não pode trabalhar somente com uma norma de uma determinada etapa do processo de FDC. O ideal é que as outras partes estejam envolvidas e bem detalhadas numa política que englobe todas as etapas da FDC.

Miranda (2007, p. 9) traz afirmações sobre o procedimento da seleção nas $\mathrm{BU}$, abordando a necessidade da participação do corpo docente, discente e os técnicos administrativos. A autora aborda também as questões qualitativas e quantitativas relacionadas ao Ministério da Educação (MEC), ressaltando a necessidade de empregar os critérios de seleção contidos na política de seleção.

Há docentes que, pela demora do recebimento dos livros na biblioteca, em função da escassez de recursos financeiros e das burocracias, não dão importância em atuar com os bibliotecários na formulação das listas atualizadas de bibliografias. Boa parte dos professores só fazem essas listas porque é uma exigência da instituição. Em outros casos "[...] o corpo docente nem sempre dispõe do tempo necessário para trazer à biblioteca sua colaboração eficaz" (LITTON, 1975, p. 36).

O bibliotecário precisa conhecer a literatura científica dos cursos oferecidos pela unidade organizacional em que atua e incentivar os professores a fazerem as listas de bibliografias, pois é fundamental a participação do corpo docente. A autora destaca que:

A seleção numa biblioteca universitária deve ser feita em parceria dos bibliotecários com corpo docente, pois estes dominam a literatura nas suas respectivas áreas e podem assim, selecionar criteriosamente o material a ser obtido, arrolando-os através dos Planos de Ensino. Os bibliotecários devem permanecer cientes das exigências do MEC para composição do acervo no que se refere à qualidade e à quantidade mínima de títulos e exemplares. No tocante à quantidade, deve ser determinado um percentual de exemplares destinados à literatura básica e outro para a literatura complementar (MIRANDA, 2007, p. 9).

Realizando uma breve análise da citação acima, a autora aborda das 
questões qualitativas e quantitativas relacionadas ao MEC, porém há outros pontos que devem ser elencados, já que as BU não só devem trabalhar com as exigências do MEC, mas também precisam empregar os critérios de seleção pressupondo que já estejam dentro da política de seleção. A avaliação do MEC é importante para as BU, pois é uma obrigação de todo o bibliotecário prestar contas do acervo em geral, mas não deve ser a única diretriz na seleção dos materiais bibliográficos.

Para selecionar um acervo bibliográfico nas $\mathrm{BU}$, é preciso cumprir funções que estejam adequadas à realidade do contexto da instituição, respeitando 0 público, a estrutura física, as condições econômicas, as questões culturais e as necessidades informacionais do seu público.

A seleção de livros nas BU é importante para a eficiência da aquisição, uma consiste na causa e a outra no efeito. Para que se tenha uma ideal seleção de materiais bibliográficos, os objetivos da instituição, voltados principalmente para pesquisa, ensino e extensão devem ser a base na formação dos critérios e das políticas.

\subsection{Critérios de Seleção para Livros}

Os critérios de seleção são fundamentais para o crescimento racional e equilibrado do acervo que vise primordialmente a comunidade (MIRANDA, 2007; SANTA ANNA, 2016; 2017; TAVARES, 2015; VERGUEIRO, 2010).

Maciel e Mendonça (2006) apresentam um fluxograma de seleção de documentos, em que o estabelecimento dos critérios são o ponto de partida e a organização dos instrumentos de seleção ocupam a posição posterior. Vergueiro (2010, p. 17) traz uma colocação preliminar antes de definir esses critérios. $O$ autor prioriza as pessoas envolvidas na elaboração dos critérios, enfatizando que todos devem trabalhar "[...] de modo racional, dispostos a discutir objetivamente a aplicação ou aplicabilidade desses critérios." A posição do autor é coerente, pois o ideal é que os participantes estejam em um comum acordo, atendendo os estudos já antes realizados dos usuários e aos objetivos da instituição, para que não haja posteriormente desentendimentos em relação a 
procedência do estabelecimento dos critérios de seleção.

Pinheiro (2017) realizou um estudo minucioso sobre o desenvolvimento de coleções nas BU apontando os aspectos antigos e recentes. Diante disso, a autora analisou cada etapa da FDC. Na parte da seleção em relação aos critérios, ela afirma que o padrão do MEC é o mais utilizado, ocasionando numa preocupação acerca da atuação do público e de especialistas que tenham o domínio sobre os assuntos que envolvem a biblioteca. O autor também aponta para questões de acessibilidade, número de usuários e de alunos matriculados, citações em bibliografias nacionais e internacionais.

Vergueiro (2010) propôs alguns critérios que são muito usados pelos bibliotecários de acordo com o grau de utilização, mas o autor realça que cada biblioteca não se deve pautar unicamente nesses critérios, pois cada uma precisa criar os seus critérios considerando o contexto da unidade organizacional.

O Quadro 1 apresenta treze critérios de acordo com a abordagem da adequação ao usuário, do conteúdo dos documentos e dos aspectos adicionais do documento, que são os mais aplicados nas unidades organizacionais, principalmente nas $\mathrm{BU}$.

\section{Quadro 1 - Principais critérios de seleção}

\begin{tabular}{|c|c|}
\hline ABORDAGEM & CRITERIOS \\
\hline \multirow{5}{*}{ Conteúdo dos documentos } & Autoridade \\
\hline & Precisão \\
\hline & Imparcialidade \\
\hline & Atualidade \\
\hline & Cobertura/Tratamento \\
\hline \multirow[t]{4}{*}{ Adequação ao usuário } & Conveniência \\
\hline & Idioma \\
\hline & Relevância/Interesse \\
\hline & Estilo \\
\hline \multirow[t]{3}{*}{ Aspectos adicionais do documento } & Características físicas \\
\hline & Aspectos especiais \\
\hline & Contribuição potencial \\
\hline
\end{tabular}

Inf. Inf., Londrina, v. 26, n. 1, p. 415 - 439, jan./mar. 2021. 


\section{Custo}

Fonte: Vergueiro (2010).

De acordo com a pesquisa de Tallman e Work (2018) o autor William Katz em seu livro Collection Development: the selection of materials for libraries, determinou dez critérios de seleção que se adequam aos que foram colocados por Vergueiro (2010) no Quadro 1. Os critérios são: 1) objetivo, escopo e público, 2) dificuldade, 3) autoridade, honestidade e credibilidade do autor e editor, 4) assunto, 5) comparação, 6) pontualidade, 7) formato, 8) preço, 9) apoio curricular e 10) demanda.

William Katz enfatiza primeiramente na comunidade, na realidade da biblioteca, sendo oposto a Vergueiro (2010) e Maciel e Mendonça (2006). O estudo da comunidade sempre deve ser um dos primeiros passos nos critérios de seleção, pois o bibliotecário que não conhece o seu público ficará perdido na hora de selecionar as obras.

\section{PROCEDIMENTOS METODOLÓGICOS}

Para uma investigação mais estruturada, a pesquisa foi constituída nas etapas quantitativa e qualitativa. Cooper e Schindler (2011) afirmam que as análises quantitativas e qualitativas se complementam, com a finalidade de obter uma maior compreensão e explanação acerca do objeto de estudo, possibilitando o enriquecimento do trabalho.

Vale ressaltar que o cerne da pesquisa está relacionado em aspectos teóricos e práticos dos critérios de seleção de livros, tendo por finalidade estudar a prática profissional respeitando o tópico sete do Art. $1^{\circ}$, parágrafo único da Resolução 510, de sete de abril de 2016 do Comitê de Ética quando aborda sobre a pesquisa que não será registrada e nem avaliada pelo sistema Comitês de Ética em Pesquisa (CEP) / Comissão Nacional de Ética em Pesquisa (CONEP) aquela "[...] que objetiva o aprofundamento teórico de situações que emergem espontânea e contingencialmente na prática profissional, desde que não revelem dados que possam identificar o sujeito." (CONSELHO NACIONAL DE SAÚDE, 2016, p. 2). 


\subsection{ETAPa QUANTITATIVA}

A etapa quantitativa tem como objetivo de "[...] obter melhor entendimento do comportamento de diversos fatores e elementos que influem sobre determinado fenômeno." (RICHARDSON, 2010, p. 71), permitindo o levantamento de dados sobre um determinado grupo ou problemática dentro de uma amostra representativa, para que os resultados sejam válidos. Esse método utiliza-se de técnicas estatísticas para o tratamento dos dados alcançados (RICHADSON, 2010).

O universo desta pesquisa abarcou os bibliotecários que atuam nas Instituições de Ensino Superior (IES) públicas Federais e Estaduais do Brasil incluindo o Distrito Federal com foco no setor de coleções, totalizando 52 Universidades Federais e 36 Universidades Estaduais. Houve uma participação de 140 profissionais da informação, cuja distribuição por região do país pode ser vista na Tabela 1. Apenas 81 bibliotecários relataram ter experiência profissional na área de FDC, porém, um participante não teve os seus dados contemplados no estudo, ocasionado pelo fato das respostas não estarem em consonância com as diretrizes do questionário, impossibilitando as análises.

Tabela 1 - Respondentes por região

\begin{tabular}{|c|c|}
\hline REGIÃO & RESPONDENTES \\
\hline SUDESTE & 42 \\
\hline SUL & 23 \\
\hline NORDESTE & 43 \\
\hline NORTE & 10 \\
\hline CENTRO-OESTE & 22 \\
\hline
\end{tabular}

Fonte: Dados coletados (2019).

Para a presente pesquisa a coleta de dados foi feita na forma transversal tendo uma única fase para sua realização (MALHOTRA, 2006). O questionário foi elaborado de acordo com a literatura científica nacional e internacional sobre os critérios de seleção através do Formulários Google, para isso foi realizado antes uma matriz elencando todos os critérios abordados pelos autores. A coleta foi realizada entre 13 de maio de 2019 à 27 de maio de 2019. 
Esse instrumento teve uma estrutura de sete seções totalizando 27 perguntas, sobre as quais os bibliotecários puderam responder em forma de avaliação percentual entre 0\% a 100\% o grau de importância dos critérios de seleção, possibilitando uma liberdade aos respondentes entre as respostas das variáveis. No total foram 23 critérios de seleção (variáveis independentes) avaliados. A quantidade de variáveis inseridas na pesquisa pode ser compreendida e fundamentada por Kline (1979), que certifica que é necessário pelo menos o dobro de respondentes em relação às variáveis investigadas. Diante disso, a relação entre respondentes e variáveis está dentro da medida requerida, com indicador aceitável de 80/23 $=3,47$.

A análise da confiabilidade foi realizada através do software Statistica, por meio do cálculo do alfa de Cronbach. De acordo com Hair Jr. et al. (2009), o limite inferior para o alfa de Cronbach normalmente aceito é de 0,70 , ressaltando que nas pesquisas exploratórias o coeficiente tende a diminuir para 0,60. $O$ valor do alfa foi 0,89 , o qual demonstra que o questionário possui uma confiabilidade válida.

Uma regressão linear foi utilizada para averiguar o fator acerca da importância dos critérios de seleção e descobrir qual a influência dele nas tomadas de decisões. Para tanto, foram observados os seguintes fatores condicionantes. O histograma dos resíduos apresentou distribuição normal. $O$ valor do teste de Durbin-Watson, nesta pesquisa foi de 2,09, sendo próximo de 2 indicando a inexistência de autocorrelação. Foi realizado teste para verificar se havia multicolinearidade entre as variáveis independentes, o VIF. Valores de VIF superiores a 10 indicam problema de multicolinearidade (O'BRIEN, 2004). Os coeficientes da pesquisa atenderam aos parâmetros.

Observados os fatores condicionantes, foram selecionadas as variáveis independentes que fizeram parte do modelo. No caso da análise de regressão linear utilizou-se como variável dependente: o uso dos critérios de seleção para tomada de decisões acertadas quanto ao desenvolvimento de coleções das bibliotecas, como variáveis independentes foram elencadas: Autoridade $\left(x_{1}\right)$; Precisão $\left(\mathrm{x}_{2}\right)$; Atualidade da informação $\left(\mathrm{x}_{3}\right)$; Cobertura/Tratamento $\left(\mathrm{x}_{4}\right)$; Imparcialidade ( $\left.x_{5}\right)$; Qualidade do conteúdo $\left(x_{6}\right)$; Relevância histórica $\left(x_{7}\right)$; 
Publicações originais $\left(\mathrm{x}_{8}\right)$; Conveniência $\left(\mathrm{x}_{9}\right)$; Idioma/Língua acessível $\left(\mathrm{x}_{10}\right)$; Relevância/Interesse ( $\left.x_{11}\right)$; Formatos acessíveis às pessoas com deficiência ( $\left.\mathrm{x}_{12}\right)$; Estilo $\left(\mathrm{x}_{13}\right)$; Características físicas/Estado de conservação física ( $\left.\mathrm{x}_{14}\right)$; Aspectos especiais ( $\left.\mathrm{x}_{15}\right)$; Contribuição potencial ( $\left.\mathrm{x}_{16}\right)$; Custo/Custo justificável $(\mathrm{x} 17)$; Disponibilidade do material na coleção de outro serviço de informação na Universidade ( $\left.\mathrm{x}_{18}\right)$; Atualização de formatos e suportes ( $\left.\mathrm{x}_{19}\right)$; Parâmetros do MEC para os cursos de graduação ( $\mathrm{x}_{20}$ ); Quantidades mínimas recomendadas pelos órgãos de avaliação e credenciamento dos cursos da instituição ( $\left.\mathrm{x}_{21}\right)$; Parâmetros estabelecidos pelos Programas de Pós-graduação ( $x_{22}$ ); Citação em bibliografias nacionais e/ou internacionais ( $\mathrm{x}_{23}$ ). A seleção das variáveis independentes se deu a partir do método forward stepwise.

A Tabela 2 apresenta os dados da qualidade do modelo de regressão:

Tabela 2 - Qualidade do modelo de regressão

\begin{tabular}{|c|c|c|c|c|c|}
\hline $\mathbf{R}$ & $\mathbf{R}^{2}$ & $\begin{array}{c}\mathbf{R}^{2} \\
\text { ajustado }\end{array}$ & $\mathbf{F}(\mathbf{7 , 7 1 )}$ & $\begin{array}{c}\text { Erros de } \\
\text { estimativas } \\
\text { estandardizado } \\
\mathbf{s}\end{array}$ & $\mathbf{p}$ \\
\hline 0,53 & 0,28 & 0,21 & 4,01 & 16,755 & $<01$ \\
\hline
\end{tabular}

Fonte: Dados coletados (2019).

Para esse modelo de regressão o resultado do $R^{2}$ ajustado foi de 0,21 , o que significa que ela explica $21 \%$ da variação possível na variável dependente.

\subsection{ETAPA QuALITATIVA}

Foi realizada uma etapa qualitativa com o propósito de entender melhor o resultado da análise anterior, através do estudo dos elementos subjetivos das atividades práticas do processo de seleção.

Nesta etapa metodológica, buscou-se visualizar de uma perspectiva mais próxima como os critérios de seleção de livros estão sendo aplicados nas BU. As entrevistas foram de caráter semiestruturado e foram realizadas via telefone devido à localização geográfica dos entrevistados.

O universo da pesquisa abrangeu bibliotecários que participaram da etapa quantitativa e que tivessem experiência na área de FDC das Instituições de 
Ensino Superior (IES) públicas, totalizando oito Universidades Federais e sete Universidades Estaduais do Brasil incluindo o Distrito Federal.

A seleção da amostra foi de quinze entrevistas semiestruturadas sendo distribuídas pelas cinco regiões do Brasil como mostra na Tabela 3:

Tabela 3 - Quantidade de bibliotecários entrevistados por região

\begin{tabular}{|cc|}
\hline REGIÃO & QUANTIDADE DE ENTREVISTA \\
\hline SUDESTE & 4 \\
\hline SUL & 4 \\
\hline NORDESTE & 3 \\
\hline NORTE & 2 \\
\hline CENTRO-OESTE & 2 \\
\hline
\end{tabular}

Fonte: Dados coletados (2019).

A coleta foi realizada entre 04 de julho de 2019 a 02 de setembro de 2019 tendo sido gravadas em meio digital e posteriormente transcritas. Foi acordado com os entrevistados, que seus nomes não seriam divulgados neste trabalho.

A análise das entrevistas foi efetuada através da definição e arranjo das categorias analíticas. As resoluções foram interpretadas cada uma, segundo o método da análise pragmática da linguagem desenvolvido por Mattos (2005), correlacionando-as com os resultados adquiridos através do referencial teórico do presente estudo. Por fim, foram debatidos os resultados e realizadas as considerações finais sobre estes.

\section{ANÁLISE DOS DADOS}

Na etapa quantitativa a análise consistiu na regressão linear múltipla, com o objetivo de identificar quais os critérios de seleção foram os mais significativos para o processo de seleção de livros. Na parte qualitativa foi realizada a análise pragmática da linguagem que revelou os depoimentos dos bibliotecários acerca da seleção e dos critérios devido ao resultado da análise quantitativa. 


\subsection{ETAPA QuANTITATIVA}

A regressão linear múltipla é uma técnica que permite verificar a relação linear entre a variável dependente e as suas variáveis independentes. A partir dessa técnica é possível obter identificar de que forma a variável independente contribui para o desenvolvimento da seleção de livros.

Portanto, a regressão linear múltipla descreve o desempenho de uma variável dependente a partir de uma função matemática com fundamento no valor de duas ou mais variáveis independentes.

O modelo gerado apresentou a seguinte variável independente:

\section{Tabela 4 - Modelo de regressão gerado}

\begin{tabular}{|c|c|c|c|c|c|}
\hline Variável & $\mathbf{b}^{*}$ & $\begin{array}{c}\text { Erros de estimativas } \\
\text { estandardizados de b* }\end{array}$ & $\mathbf{b}$ & $\mathbf{t}$ & $\mathbf{p}$ \\
\hline Intercepto & & & 64,14 & 4,82 & $<01$ \\
\hline $\begin{array}{c}\text { Atualidade da } \\
\text { informação }\end{array}$ & 0,34 & 0,12 & 0,35 & 2,83 & $<01$ \\
\hline
\end{tabular}

Fonte: Dados coletados (2019).

Onde $b^{*}$ é o coeficiente que representa se a variável independente tem uma conexão com a variável dependente, t é o teste parcial e o p que representa a significância estatística do resultado da regressão linear, tendo limite inferior de $-5 \%$.

A variável atualidade da informação refere-se à terceira pergunta da seção três (critérios em relação ao conteúdo). A mesma expressou um coeficiente $b^{*}$ de 0,34 , indicando uma direta relação com a variável dependente, ao ponto em que auxilia na explanação de como esse critério tem um forte impacto no processo da seleção de livros das BU.

Vergueiro aponta que o critério da atualidade da informação afeta diretamente a atividade de seleção, uma vez que "uma informação desatualizada perde muito de seu valor". (2010, p. 20). O autor ratifica que os bibliotecários precisam estar atentos às edições atualizadas, avaliando sempre de forma clara a informação nova. 
Para diversos autores o atendimento às demandas impostas pelo MEC (Universidades Federais) e pelo Conselho Estadual de Educação (Universidades Estaduais) faz emergir o critério de atualidade da informação através da obtenção das edições mais recentes das obras (DIAS; PIRES, 2003; MIRANDA, 2007; PINHEIRO, 2017; VERGUEIRO, 2010). Todavia, os dados coletados mostram mais do que isto, este critério é o mais significativo para os bibliotecários das instituições públicas de ensino superior brasileiras. Pinheiro (2017) já alertava sobre a ausência de outros critérios, tais como os relacionados à participação da comunidade e de uma averiguação de especialistas no assunto.

Dentro do contexto acadêmico que requer em todo o tempo de informações atualizadas e confiáveis, sendo as grandes geradoras dos registros de informações científicas, o papel da atualização é inerente e necessário de acordo com a área do conhecimento para a qual a biblioteca atua. Diante disso, é através da atualização que novas maneiras de fazer ciência em prol da comunidade pode refletir em resultados benéficos para os indivíduos independente da área em que atua, seja na saúde, nas exatas, nas ciências sociais.

\subsection{ETAPA QualitaTiva}

Neste tópico serão discutidas as percepções dos entrevistados sobre o processo de seleção em suas instituições. As entrevistas buscaram um maior entendimento sobre o impacto do critério atualidade da informação de acordo com os envolvidos no processo de FDC trazendo depoimentos acerca da importância do processo de seleção de livros nas BU. Cada entrevistado recebeu a identificação de uma letra do alfabeto de $A$ até $P$.

- Processo de seleção de livros no contexto das BU

Neste momento observa-se que o processo de seleção é semelhante ao processo de aquisição e depende das bibliografias básicas devido ao MEC e ao 
Conselho Estadual de Educação, na qual o corpo docente tem um papel fundamental. As etapas de FDC que foram mencionadas durante os relatos foram a aquisição, o desbaste e o descarte.

Quando um professor solicita um material e a gente registra aquele material para futuramente ele ser adquirido, ele passou por um processo de comprar porque o docente ele é o especialista da área [...] (Entrevistado E).

[...] a questão da seleção ela é feita [...] ela é encaminhada pelo próprio professor quando manda para nós a lista [...] eles já fazem uma seleção título a título (Entrevistado M).

Para outros entrevistados o bibliotecário que atua na seleção tem o poder na tomada de decisão, na qual o processo de seleção é um órgão administrativo que precisa estar ligado com as necessidades de seu público. O profissional da informação que está nessa área é um dos responsáveis para a qualidade do acervo da biblioteca, na qual precisa ser produtivo, conhecer o mundo do mercado editorial e seus usuários.

[...] Esse processo é fundamental porque a partir do momento em que você tem essa tomada de decisão de incluir ou excluir, você tem esse poder. Então, isso é fundamental para que você tenha uma qualidade das bibliotecas. Então, o profissional que atua nesse setor ele tem que estar sempre em sintonia com o usuário, em sintonia com a comunidade e com o que está acontecendo no mercado, na questão do acervo (Entrevistado C).

Eu acho que é um processo que tem muita proximidade com a comunidade né [...] com os usuários [...] é um processo que é bem importante a gente conhecer a nossa comunidade e ver qual a necessidade dela [...], para que tenha acesso aos documentos como os programas dos cursos, o Projeto Político Pedagógico, onde tem as bibliografias [...] e buscar sempre adquirir tudo o que está previsto naquilo [...] e também fazendo um meio campo com os professores para atualizar aquilo [...] (Entrevistado G).

Neste contexto, pode-se perceber que a seleção de livros é inerente aos critérios de seleção que precisam estar bem estruturados e claros na política de FDC, respeitando a particularidade que esse processo terá em cada biblioteca, como ilustra o entrevistado $\mathrm{J}$ "só que tem que ter os critérios, tem que deixar bem claro [...] a gente estuda todos os nossos critérios de seleção desse material". Este argumento é reforçado pelo entrevistado $\mathrm{P}$, que se mostra preocupado inclusive com a falta de espaço na biblioteca para guarda dos livros "seleção aqui 
é sempre criteriosa mesmo de acordo com os usuários, a gente tem essa preocupação por ter falta de espaço, a gente não pode ficar com livros que não vão ter saída".

De acordo com os relatos o processo de seleção proporciona uma informação atualizada que é um dos critérios utilizados nas tomadas de decisões. $\mathrm{O}$ entrevistado $\mathrm{H}$ ressalta a importância da informação atualizada para o estudo dos alunos "vai possibilitar ao seu usuário, ao seu aluno, o acesso à uma informação atualizada [...] ao conhecimento. Contudo, a seleção apenas por este critério gera dúvidas se está sendo suficiente para atender as demandas dos usuários das bibliotecas, como ilustra o entrevistado $\mathrm{O}$.

[...] a gente seleciona aquilo que a gente vê que precisa de atualização [...] aquilo que tem muita procura [...] a gente seleciona dessa forma, a forma não é adequada, mas é a forma que a gente consegue fazer (Entrevistado $\mathrm{O}$ ).

Neste contexto, os entrevistados deixam claro que o processo de seleção de livros é um complexo e intelectual. Como relata o entrevistado $E$ "o processo de seleção não é um processo como as pessoas acham, um processo manual", não sendo tecnicista e feito por um único bibliotecário, mas sim através do envolvimento de vários grupos de indivíduos.

Eu acho muito complexo, não é uma atividade simples, envolve várias pessoas, várias situações. Então assim como a gente não tem como fazer uma seleção qualitativa do acervo, a gente não pode estar trabalhando o tempo todo e definindo, a gente depende de outras pessoas (Entrevistado F).

A seleção ela não é um trabalho simples, não é simplesmente olhar um livro e: Ah! Está danificado [...] está muito antigo. A gente tem que verificar um bocado de coisas que é uma obra rara, verifica o contexto dele, porque se for muito importante, se a gente julgar que é muito importante, a gente vai ter que restaurar aquele livro para o usuário. Então assim, você não pode ficar disperso, não pode ter a mente fechada, tem que esgotar todas as possibilidades para saber se realmente o teu usuário ou o usuário de outra biblioteca não vai usar (Entrevistado L).

Os relatos apresentados demonstram que o processo de seleção é caracterizado como uma atividade decisória como já abordava Vergueiro (2010). $O$ ato de escolher título a título vai muito além de aspectos técnicos, envolve um contexto sociocultural, na qual o bibliotecário selecionador precisa conhecer o seu público e os objetivos da instituição para qual trabalha. 
Esse processo requer esforço intelectual, dedicação, conhecimento sobre o mercado editorial, uma boa interação com os usuários e principalmente com o corpo docente que detém de um conhecimento mais aprofundado sobre os assuntos.

\section{- Critério atualidade da informação}

A atualização da informação foi um dos pontos fundamentais dos relatos dos entrevistados, como explica o entrevistado N sobre o acervo "é sempre atualizado, sempre se compra a última versão daquele livro". Nota-se que os bibliotecários priorizam em manter o acervo atualizado, possibilitando uma interação com a comunidade acadêmica, visando principalmente o crescimento qualitativo do acervo.

[...] a gente procura sempre colocar essa importância da atualização do acervo para a comunidade acadêmica e a gente procura interagir com eles dessa forma [...] e mostrando para eles a importância de ter o nosso acervo não só cheio de título, mas um acervo atualizado (Entrevistado J).

Olha, a gente tem a questão do conteúdo, a questão da atualização, principalmente a atualização, porque tem áreas afins que usam os mesmos livros [...] (Entrevistado F).

Os entrevistados ressaltam o valor que dão ao critério atualização para composição do acervo. $O$ entrevistado $C$ diz que "a gente busca na medida do possível ir buscando as edições mais atuais dos livros, quando é feito um lançamento a gente tem que estar sempre atento no mercado editorial mesmo". Os respondentes $\mathrm{D}$ e $\mathrm{H}$ também ilustram esta linha de priorizar a aquisição das edições mais novas das obras.

[...] a edição ela é antiga, a gente tem uma edição mais nova, mas a gente sempre prioriza estar fazendo a aquisição do mais novo (Entrevistado D).

Então, a gente vai e pega aquele título que tem a edição nova e vai ficar o acervo mais atualizado (Entrevistado $\mathrm{H}$ ).

Esta busca é feita inclusive verificando título por título das bibliografias básicas e complementares, para buscar as edições mais recentes.

[...] A gente vai na internet, faz a busca daquele livro, vê qual é a edição mais atualizada para que eles venham mais atualizados o possível. Às vezes você tem o mesmo livro que é de uma 
edição anterior, mas a gente procura sempre o que é mais atualizado (Entrevistado A).

Os entrevistados afirmaram que mesmo em obras que as mudanças no conteúdo são mínimas, há a busca pela aquisição das mais recentes. Isto está ligado diretamente aos parâmetros externos, ou seja, ao MEC e ao Conselho Estadual de Educação, na qual uma das diretrizes consiste em um acervo atualizado que garanta informações confiáveis e de qualidade.

Foi relatado que os bibliotecários precisam ter um cuidado redobrado em relação as áreas que se desatualizam numa velocidade acentuada, seguindo o fluxo dessas mudanças para trazer a biblioteca informações que agreguem conhecimentos inovadores em prol da sociedade, principalmente no ambiente das BU. O bibliotecário que atua na seleção de livros tem que estar em sintonia com o contexto sociocultural atual de sua comunidade acadêmica, com o objetivo de inserir no acervo informações pertinentes a esse público, trazendo-os para o ambiente da biblioteca, tornando-os usuários assíduos em utilizar cada vez mais essa unidade organizacional.

Esta preocupação também foi justificada pelo caráter social, por conta do ingresso dos estudantes através das cotas, que possuem menos capacidade financeira de adquirir seus próprios livros, ficando dependente da disponibilidade destes nas bibliotecas. O entrevistado $E$ afirma que "tinham alguns cursos, por exemplo, que não usava muito a biblioteca, como Direito, Medicina, que tinha mais condições de estar adquirindo material, hoje, com as cotas de escolas públicas, por exemplo, essa característica mudou".

Mesmo no cenário de restrição orçamentária as avaliações de curso realizadas pelo MEC continuam forçando os bibliotecários, como disse o entrevistado $\mathrm{E}$ "a correr atrás de alternativas para tentar adquirir o material, às vezes pode não ser na quantidade que o instrumento indica", a fim de assegurar livros com edições mais recentes. Sendo a doação de livros uma alternativa.

\section{CONSIDERAÇÕES FINAIS}

Entende-se que a seleção de livros é um processo inerente nas unidades organizacionais que sempre irá existir independente das tecnologias, pois essa 
atividade é caracterizada como complexa, intelectual, multidisciplinar, carregada de relações interpessoais que exige um contato do bibliotecário com os seus usuários.

Conforme evidenciado nas publicações nacionais as BU que ainda não têm uma política de FDC podem ter dificuldades na hora de tomarem decisões. Estes estudos, então, majoritariamente, versam sobre a comparação dos procedimentos utilizados para a formação e desenvolvimento da coleção de material nas bibliotecas universitárias com os preceitos da literatura da área.

Dentro deste contexto, os critérios são ferramentas importantes na tomada de decisão no processo de seleção, pois o bibliotecário necessita de políticas bem estruturadas e passíveis de atualizações que possam auxiliar no desenvolvimento racional e qualitativo da biblioteca. Todavia, uma vez que os critérios de seleção de livros impactam de maneira diferente, quais são indispensáveis, na visão dos bibliotecários, para o processo de tomada de decisão no ambiente das bibliotecas públicas universitárias brasileiras?

Em que pese à observância de inúmeros critérios na literatura, pôde-se perceber que uma única variável independente influencia no processo de seleção de livros - o critério de atualidade da informação, que explica o estudo como um todo. Um acervo atualizado é o ponto crucial na tomada de decisão, principalmente por conta dos parâmetros externos que são as avaliações do MEC e do Conselho Estadual de Educação que interferem no uso desse critério.

Manter a informação atualizada se mostra como a função mais importante do bibliotecário nestas instituições, no tocante ao desenvolvimento de coleções. Assim, é preciso de uma atenção redobrada em relação à lista bibliográfica básica e complementar e ao mercado editorial. O profissional da informação adquire responsabilidades em verificar se realmente a fonte na qual a informação foi veiculada é atualizada, para assegurar um serviço de confiabilidade à comunidade acadêmica, especialmente aos discentes e ao público potencial que não tem condições financeiras de adquirir livros caros que estão ano após ano sendo atualizados.

As limitações do estudo foram principalmente relacionadas a falta de informações atualizadas no site das BU, o que impossibilitou o retorno de boa 
parte dos questionários. Na parte das entrevistas o recebimento dos e-mails não teve uma resposta plausível, ocasionando na busca dos contatos telefônicos das BU para a realização das entrevistas.

Esta pesquisa gera novos estudos, visto que o assunto necessita ter uma continuidade percorrendo não somente os livros, mas os diversos formatos existentes nas BU (DVD's, CD's, e-books, obras raras, folhetos, periódicos), analisando como o processo de seleção se dá nesses meios e de como os critérios estão sendo aplicados nessas unidades organizacionais.

Procedendo disto, acredita-se que os futuros trabalhos irão ajudar no aprofundamento e reconhecimento da seleção, garantindo uma acentuada solidificação no que tange as bases teóricas e práticas do tema.

\section{REFERÊNCIAS}

ALMEIDA, Bonifácio Chaves de; MACHADO, Raymundo das Neves. Development of the informational collection of IFBA in the view of the responsible for libraries. Digital Journal of Library and Information Science, Campinas, SP, v. 17, p. 1-22, 2017. Disponível em: https://bit.ly/329k3S8. Acesso em: 18 fev. 2020.

BRAYNER, Aquiles Alencar. Rompendo o mito do silêncio. In: BRAYNER, Cristian. A biblioteca de Foucault: reflexões sobre ética, poder e informação. São Paulo: É realizações, 2018. p. 17-22.

CONSELHO NACIONAL DE SAÚDE. Resolução n 510/2016, de 07 de abril de 2016. Dispõe sobre as normas aplicáveis a pesquisas em Ciências Humanas e Sociais cujos procedimentos metodológicos envolvam a utilização de dados diretamente obtidos com os participantes ou de informações identificáveis ou que possam acarretar riscos maiores do que os existentes na vida cotidiana, na forma definida nesta Resolução. Brasil: Conselho Nacional de Saúde, 2016. Disponível em: https://bit.ly/3bZ7Nse. Acesso em: 9 out. 2019.

COOPER, Donald R.; SCHINDLER, Pamela S. Métodos de pesquisa em administração. 10. ed. Porto Alegre: Bookman, 2011.

DIAS, Maria Matilde Kronka; PIRES, Daniela. Formação e desenvolvimento de coleções de serviços de informação. São Carlos: EdUFSCar, 2003.

DRURY, Francis Keese Wynkoop. Book Selection. Chicago: American Library Association, 1930. Disponível em:

https://babel.hathitrust.org/cgi/pt?id=uc1.b4209483;view=1up;seq=9. Acesso em: 22 mar. 2019. 
EDUVIRGES, Joelson Ramos. O processo de formação e desenvolvimento de coleções da Biblioteca Central da Universidade Estadual do Piauí. Múltiplos Olhares em Ciência da Informação, Minas Gerais, v. 3, n. 2, 2013. Disponível em: https://brapci.inf.br/index.php/res/v/60920. Acesso em: 18 fev. 2020.

FARIA, Cleide Vieira de. Seleção de materiais bibliográficos para a modalidade de aquisição doação: um relato de experiência da Biblioteca Central da Universidade Federal de Minas Gerais. Revista Brasileira de

Biblioteconomia e Documentação, São Paulo, v. 13, n. esp., p. 1435-1449, 2017. Disponível em: https://rbbd.febab.org.br/rbbd/article/view/1023. Acesso em: 18 fev. 2020.

FIGUEIREDO, Nice Menezes de. Seleção e aquisição: da visão clássica à moderna aplicação de técnicas bibliométricas. Ciência da Informação, Brasília, v. 12, n. 2, p. 37-50, jul./dez. 1984. Disponível em: http://revista.ibict.br/ciinf/article/view/202/202. Acesso em: 21 mar. 2019.

HAIR Jr., Joseph F; BLACK, W. C.; BABIN, B. J.; ANDERSON, R. E.; TATHAM, R. L. Análise multivariada de dados. 6. ed. Porto Alegre: Bookman, 2009.

KITAJIMA, Mitsuro; BABA, Kensuke; MINAMI, Toshiro. An evaluation of book selection in a university library by loan record analysis. International Journal of Information and Education Technology, Singapore, v. 5, n. 10, p. 728731, oct. 2015. Disponível em: http://www.ijiet.org/papers/601-D029.pdf. Acesso em: 22 mar. 2019.

KLINE, Paul. Psychometrics and psychology. London: Acaderric Press, 1979.

LITTON, Gaston. Como se forma um acervo bibliográfico. São Paulo: McGraw-Hill do Brasil, 1975. p. 1-97.

MACIEL, Alba Costa; MENDONÇA, Marília Alvarenga Rocha. Bibliotecas como organizações. Rio de Janeiro: Interciência; Niterói: Intertexto, 2006.

MALHOTRA, Naresh K. Pesquisa de marketing: uma orientação aplicada. 4 ed. São Paulo, SP: Bookman, 2006.

MATTOS, Ana Maria; DIAS, Eduardo José Wense. Desenvolvimento de coleções em bibliotecas universitárias: uma abordagem quantitativa.

Perspectivas em Ciência da Informação, Minas Gerais, v. 14, n. 3, p. 38-60, set./dez. 2009. Disponível em: https://bit.ly/39MQJDU. Acesso em: 18 fev. 2020.

MATTOS, Pedro Lincoln Carneiro Leão de. A entrevista não-estruturada como forma de conversação: razões e sugestões para sua análise. Revista de Administração Pública, Rio de Janeiro, v. 39, n. 4, p. 823-846, 2005. Disponível em: https://bit.ly/37FdEzB. Acesso em: 02 nov. 2019. 
MELO, Lílian Lima de Siqueira; MARQUES, Denílson Bezerra; PINHO, Fabio Assis. A biblioteca universitária e a sua atuação frente à mutabilidade de paradigmas. InCID: Revista de Ciência da Informação e Documentação, Ribeirão Preto, v. 5, n. 1, p. 69-89, mar./ago. 2014. Disponível em: http://www.revistas.usp.br/incid/article/view/64069. Acesso em: 12 mar. 2019.

MIRANDA, Ana Cláudia Carvalho de. Desenvolvimento de coleções em bibliotecas universitárias. Revista Digital de Biblioteconomia e Ciência da Informação, Campinas, v. 4, n. 2, p. 01-19, jan./jun. 2007. Disponível em: https://periodicos.sbu.unicamp.br/ojs/index.php/rdbci/article/view/2018. Acesso em: 12 mar. 2019.

MIRANDA, Ana Cláudia Carvalho de; BERNARDINO, Maria Cleide Rodrigues. Gerenciamento de estoques de informação em bibliotecas públicas. Revista Brasileira de Biblioteconomia e Documentação, São Paulo, v. 15, n. 3, p. 71-93, set./dez. 2019. Disponível em: https://rbbd.febab.org.br/rbbd/article/view/1194. Acesso em: 18 fev. 2020.

MIRANDA, Ana Cláudia Carvalho de; GALLOTTI, Mônica Marques Carvalho; CECATTO, Adriano. Desafios para a biblioteca pública no processo de planejamento da formação e desenvolvimento do acervo. Encontros Bibli, Florianópolis, v. 22, n. 48, p. 15-26, jan./abr. 2017. Disponível em: https://periodicos.ufsc.br/index.php/eb/article/view/1518-2924.2017v22n48p15. Acesso em: 18 fev. 2020.

MIRANDA, Antonio. Seleção de material bibliográfico em bibliotecas universitárias brasileiras. In: MIRANDA, Antonio. Estruturas de informação e análise conjuntural: ensaios. Brasília: Thesaurus, 1980. p. 63-85.

O'BRIEN, James A. Sistemas de informação e as decisões gerenciais na era da internet. São Paulo: Saraiva, 2004.

PINHEIRO, Liliane Vieira. O desenvolvimento de coleções em bibliotecas universitárias na perspectiva dos desafios da pós-modernidade: diretrizes sob o olhar da teoria da complexidade e da análise de domínio. Orientadora: Lígia Maria Arruda Café. 2017. 297 f. Tese (Doutorado em Ciência da Informação) - Universidade Federal de Santa Catarina, Florianópolis, 2017. Disponível em: https://repositorio.ufsc.br/handle/123456789/174452. Acesso em: 12 mar. 2019.

RICHARDSON, Roberto Jarry. Pesquisa social, métodos e técnicas. São Paulo: Atlas, 2010.

SANTA ANNA, Jorge. Desenvolvimento de coleções no sistema de biblioteca da UFES: comparativo entre os modelos teóricos de Evans e Baughman e proposta de adequação ao modelo de Evans. Biblionline, João Pessoa, v. 12, n. 2, p. 141-155, 2016. Disponível em: http://www.periodicos.ufpb.br/ojs/index.php/biblio/article/view/27933. Acesso em: 12 mar. 2019. 
SANTA ANNA, Jorge. O contexto organizacional e seus reflexos no desenvolvimento de coleções: um estudo à luz das diferentes modalidades de bibliotecas. Revista ABC: Biblioteconomia em Santa Catarina, Florianópolis, v. 22, n. 1, p. 5-22, dez./mar. 2017. Disponível em:

https://revista.acbsc.org.br/racb/article/view/1267. Acesso em: 12 mar. 2019.

SILVA, Célia Aparecida Rufino Gomes; AMARAL, Roniberto Morato do; PAJEÚ, Hélio Márcio. Desenvolvimento de coleção na perspectiva da alteridade Bakhtiniana: o descarte na biblioteca universitária. Revista Brasileira de Biblioteconomia e Documentação, São Paulo, v. 14, n. 1, p. 126-151, jan./abr. 2018. Disponível em:

https://rbbd.febab.org.br/rbbd/article/view/632. Acesso em: 18 fev. 2020.

SILVA, Edilene Maria da. A influência das políticas de informação científica e tecnológica para as bibliotecas universitárias. Orientadora: Joana Coeli Ribeiro Garcia. 2009. 116 f. Dissertação (Mestrado em Ciência da Informação) - Universidade Federal da Paraíba, João Pessoa, 2009. Disponível em: http://eprints.rclis.org/14433/1/Disserta\%C3\%A7\%C3\%A3o_Cl_EDILENE_MARIA_DA_SILVA.pdf. Acesso em: 14 mar. 2019.

TALLMAN, Nathan; WORK, Lauren. Approaching appraisal: guidelines and criteria to select for digital preservation. International Conference on Digital Preservation, Boston, sept. 2018. Disponível em: https://osf.io/rj2f7/. Acesso em: 20 abr. 2019.

TAVARES, William Queiroz. Política de desenvolvimento de coleções no sistema integrado de bibliotecas da Universidade Federal de Pernambuco. Biblionline, João Pessoa, v. 11, n. 2, p. 135-149, 2015. Disponível em: http://www.periodicos.ufpb.br/ojs/index.php/biblio/article/view/25087. Acesso em: 12 mar. 2019.

VERGUEIRO, Waldomiro de Castro Santos. Desenvolvimento de coleções. São Paulo: Polis: APB, 1989. (Palavra-chave).

VERGUEIRO, Waldomiro de Castro Santos. Seleção de materiais de informação: princípios e técnicas. 3. ed. Brasília, DF: Briquet de Lemos, 2010.

WEITZEL, Simone da Rocha. Elaboração de uma política de desenvolvimento de coleções em bibliotecas universitárias. Rio de Janeiro: Interciência; Niterói: Intertexto, 2006.

\section{SELECTION OF BOOKS IN UNIVERSITY LIBRARIES UNDER THE VIEW OF BRAZILIAN LIBRARIES}

\section{ABSTRACT}

Introduction: A The selection of books is a complex process characterized by sociocultural, humanistic, technical aspects, and the criteria are fundamental to guide 
librarians in decision-making. Objective: The central objective is to identify the indispensable criteria for the decision-making process of book selection in Brazilian university public libraries. Methodology: It is configured as an exploratory research that uses the technique of content analysis and multiple linear regression in two stages: quantitative and qualitative. The sample of the quantitative stage was composed of 140 respondents and data collection was carried out through the application of questionnaires based on national and international scientific literature. In the qualitative stage, the sample consisted of 15 interviewees and the data were collected through semi-structured interviews. The analysis and diagnosis of the quantitative data were carried out from the development of the multiple linear regression method and the qualitative data were through the pragmatic analysis of language. Results: It concludes that the selection process can be explained by the variable actuality of the information described as the only one used by librarians of public university in Brazil. Conclusions: Keeping the information up-to-date proves to be a significant criteria with regard to the development of collections in these institutions.

Descriptors: Books selection. University Libraries. Librarians. Brazil.

\title{
LA SELECCIÓN DE LIBROS EN LAS BIBLIOTECAS UNIVERSITARIAS DESDE LA PERSPECTIVA DE LOS BIBLIOTECARIOS BRASILEÑOS
}

\begin{abstract}
RESUMEN
Introducción: La selección de libros es un proceso complejo caracterizado por aspectos socioculturales, humanísticos, técnicos, en que los criterios son fundamentales para orientar al bibliotecario en la toma de decisiones. Objetivo: Su principal objetivo es identificar los criterios que son indispensables para la toma de decisiones de selección de libros en las bibliotecas públicas universitarias de Brasil. Metodología: Se configura como una investigación exploratoria que utiliza la técnica de análisis de contenido y regresión lineal múltiple en dos etapas: cuantitativa y cualitativa. La muestra de la etapa cuantitativa estuvo conformada por 140 encuestados y la compilación de datos se realizó mediante la aplicación de cuestionarios basados en la literatura científica nacional e internacional. En la etapa cualitativa, la muestra estuvo conformada por 15 encuestados y los datos fueron recolectados por medio de entrevistas semiestructuradas. El análisis y diagnóstico de los datos cuantitativos se realizó a partir del desarrollo del método de regresión lineal múltiple y los datos cualitativos se realizaron mediante el análisis pragmático del lenguaje. Resultados: Se concluye que el proceso de selección se puede explicar por medio de la variable actualidad de la información descrita como la única utilizada por los bibliotecarios de las universidades públicas brasileñas. Conclusiones: Em contrapunto a la literatura, mantener la información actualizada se muestra como un criterio significativo, en lo que respecta al desarrollo de colecciones por parte de los bibliotecarios de las universidades públicas de Brasil.
\end{abstract}

Descriptores: Selección de libros. Bibliotecas Universitarias. Bibliotecarios. Brasil.

Recebido em: 27.03.2020

Aceito em: 04.02.2021 